\title{
Pendidikan Kesehatan Pencegahan Stroke dan Asam Urat pada Lanjut Usia
}

\author{
Ariyanto $^{1}$, Tina Yuli Fatmawati ${ }^{2}$ \\ ${ }^{1,2}$ Program Studi DIII Keperawatan, STIKes Baiturrahim Jambi \\ Email: riyan.stikba@gmail.com
}

Submitted : 10/04/2020

Accepted: 03/08/2020

Published: 24/11/2020

\begin{abstract}
Along with economic progress, environmental improvement and advancement of science and technology, especially in health sciences, health promotion, disease prevention and health services have resulted in increased life expectancy for humans. Our society now sees the elderly as people who are less productive, less attractive, less energetic, easy to forget, therefore to realize healthy, productive elderly people at dusk, efforts are needed, one of which is by improving healthy lifestyles. Survey conducted by the Team, The number of elderly people in Posyandu is 79 people. There are only 2 active Posyandu cadres active, the elderly rarely visit the Posyandu, and the lack of knowledge on how to cope with problems related to elderly diseases, such as gout, stroke. Therefore it is necessary to hold counseling for the Elderly to better understand about health problems in the elderly and be more active in participating in the Posyandu for the elderly so that "Healthy Elderly People in Old Age" is realized. This activity was done in May-June 2019 at the elderly in the homes of residents of RT 11 Kelurahan Kenali Asam Bawah, with the service method using a survey approach, lecture, discussion, demonstration / simulation. The results obtained by the Posyandu officers are active and able to identify the elderly and health problems of the elderly and recognize and understand frequent diseases such as gout and stroke.
\end{abstract}

Keywords: elderly, gout, health education, posyandu, stroke

\begin{abstract}
Abstrak
Seiring dengan kemajuan ekonomi, perbaikan lingkungan hidup dan majunya ilmu pengetahuan dan teknologi terutama pada ilmu kesehatan, promosi kesehatan, pencegahan penyakit dan pelayanan kesehatan mengakibatkan meningkatnya umur harapan hidup manusia . Masyarakat kita saat ini memandang para lanjut usia sebagai orang-orang yang kurang produktif, kurang menarik, kurang energik, mudah lupa, oleh karena itu untuk mewujudkan lansia yang sehat produktif diusia senja di perlukan upaya-upaya salah satunya dengan meningkatkan pola hidup sehat. Survei yang dilakukan oleh Tim, Jumlah lansia di Posyandu berjumlah 79 orang. Kader Posyandu lansia hanya ada 2 yang aktif, lansia jarang mengunjungi Posyandu Lansia, serta kurangnya pengetahuan tentang cara menanggulangi masalah-masalah yang berkaitan dengan penyakit lansia, seperti asam urat, stroke. Oleh karena itu perlu diadakan penyuluhan kepada Lansia agar lebih memahami tentang masalah-masalah kesehatan pada lansia dan lebih aktif mengikuti posyandu lansia sehingga terwujudlah "Lansia Sehat di Usia Senja". Kegiatan Pengabdian masyarakat ini dilaksanakan pada Bulan Mei-Juni 2019 pada Lansia bertempat di rumah warga RT 11 Kelurahan Kenali Asam Bawah, dengan metode pengabdian menggunakan pendekatan survei, ceramah, diskusi, demonstrasi/simulasi. Hasil yang diperoleh Kader Posyandu lansia aktif dan mampu mengidentifikasi tentang Masalah Kesehatan lansia serta Lansia mengenal dan memahami penyakit sering yang terjadi seperti Asam urat dan Stroke.
\end{abstract}

Kata Kunci: asam urat, lanjut usia, pendidikan kesehatan, posyandu, stroke 


\section{PENDAHULUAN}

Seiring dengan kemajuan ekonomi, perbaikan lingkungan hidup dan majunya ilmu pengetahuan dan teknologi terutama pada ilmu kesehatan, promosi kesehatan, pencegahan penyakit dan pelayanan kesehatan mengakibatkan meningkatnya umur harapan hidup manusia (Azizah, 2011). Pada kemajuan dibidang kedokteran, termasuk adanya penemuan obat-obatan seperti antibiotika yang mampu melenyapkan berbagai penyakit infeksi, berhasil menurunkan angka kematian bayi dan anak, memperlambat kematian, memperbaiki gizi dan sanitasi sehingga kualitas hidup dan umur harapan hidup menjadi meningkat. Akibatnya jumlah orang lansia akan bertambah dan cenderung akan meningkat dengan cepat (Nugroho, 2014).

Lanjut usia (lansia) adalah orang yang telah mencapai usia 60 tahun ke atas yang mempunyai hak yang sama dalam kehidupan bermasyarakat, berbangsa, dan ber- negara (UU RI No 13 tahun 1998). Menurut WHO (World Health Organization) membagi masa usia lanjut sebagai berikut a. Usia 45-60 tahun, disebut middle age b. Usia 60-75 tahun, disebut elderly (usia lanjut atau wreda utama) c. Usia 75-90 tahun, disebut old (tua atau wreda prawasana) d. Usia diatas 90 tahun, disebut very old (tua sekali atau wreda wasana).

Masalah kesehatan yang sering terjadi pada lanjut usia adalah Stroke dan Asam Urat. Penyakit Stroke merupakan penyebab kematian kedua dan penyebab disabilitas ketiga di dunia. WHO mendefinisikan stroke adalah suatu keadaan dimana ditemukan tanda klinis yang berkembang cepat berupa deficit neurologic yang dapat memberat dan berlangsung lama yang dapat menyebabkan kematian. Stroke juga dapat menyebabkan demensia dan depresi, ( Kemenkes RI, 2019).

Prevalensi penyakit tidak menular seperti kanker, penyakit ginjal kronis, diabetes mellitus, hipertensi dan stroke. Hasil Riset Kesehatan Dasar 2018, menyebutkan terjadi peningkatan dibanding tahun 2013, untuk penyakit stroke meningkat dari $7 \%$ menjadi $10.9 \%$ ( Kemenkes RI, 2018). Data WHO mencatat setiap tahunnya ada 13.7 juta kasus baru stroke, dan sekitar 5.5 juta kematian terjadi akibat penyakit stroke.

Masyarakat kita saat ini memandang para lanjut usia sebagai orang-orang yang kurang produktif, kurang menarik, kurang energik, mudah lupa, barangkali kurang bernilai dibandingkan dengan mereka yang masih dalam keadaan prima Kroll dan Hawkins, 1999), untuk itu dalam pembangunan nasional pemerintah telah berhasil mewujudkan hasil yang positif diberbagai bidang, yaitu adanya kemajuan ekonomi, perbaikan lingkungan hidup, kemajuan ilmu pengetahuan dan teknologi, terutama di bidang medis atau ilmu kedokteran, sehingga dapat meningkatkan kualitas kesehatan penduduk serta meningkatkan umur harapan hidup manusia. Akibatnya jumlah penduduk yang berusia lanjut meningkat dan bertambah cenderung lebih cepat atau sering disebut dengan Lansia Booming. Salah satu upaya Pemerintah dalam menyediakan fasilitas kesehatan dan penyelenggaraan upaya kesehatan antara lain adalah dengan mengadakan Posyandu. Posyandu merupakan salah satu bentuk pelayanan kesehatan yang diselenggarakan untuk dan oleh masyarakat dengan dukungan teknis dari petugas kesehatan dalam rangka pencapaian menuju Norma Kelurga Kecil Bahagia dan Sejahtera .

Survei yang dilakukan oleh Tim Pengabdian masyarakat didapat di Kelurahan Kenali Asam Bawah sudah memiliki Posyandu Lansia tetapi belum dilaksanakan secara maksimal oleh warga. Jumlah lansia di Posyandu lansia berjumlah 79 orang. Kader Posyandu lansia hanya ada 2 yang aktif, lansia jarang mengunjungi 
Posyandu Lansia karena jarak tempuh dari rumah keposyandu yang cukup jauh. Sebagian lansia kurang mengetahui tentang cara menanggulangi masalah-masalah yang berkaitan dengan penyakit lansia, seperti stroke, dan asam urat. Hal ini dikarenakan jarangnya petugas kesehatan mengadakan penyuluhan kepada lansia. Lansia yang rutin melakukan pemeriksaan kesehatannya sebesar $15 \%$. Dari beberapa hal diatas maka perlu diadakan penyuluhan bagi Lansia agar lebih memahami tentang masalah-masalah kesehatan pada lansia dan lebih aktif mengikuti posyandu lansia sehingga terwujudlah "Lansia Sehat di Usia Senja".

Pada kegiatan sebelumnya telah dilaksanakan edukasi tentang hipertensi kepada 15 orang lansia, ditemukan 6 orang lansia memiliki tekanan darah di atas normal(140/90 $\mathrm{mmHg}$ ) atau $30 \%$. Pada sesi penyampaian materi, ternyata banyak lansia yang belum memahami penyakit hipertensi.( Maemaznah, 2020). Hal ini sangat berdampak terhadap serangan stroke karena salah satu faktor resiko stroke adalah Hipertensi, sehingga tim kembali mengadakan edukasi kepada lansia tentang pencegahan stroke dan asam urat.

\section{TARGET DAN LUARAN}

Target yang dicapai pada Pengabdian masyarakat ini adalah :

a. Kader Posyandu lansia aktif dan mampu mengidentifikasi tentang Masalah Kesehatan lansia.

b. Lansia mengenal dan memahami tentang Asam urat dan Stroke

Selain menghasilkan media leaflet dan poster pengabdian masyarakat ini memiliki luaran publikasi karya tulis ilmiah dan sebagai bahan ajar pada mata kuliah keperawatan komunitas dan gerontik.

\section{METODE PELAKSANAAN}

Kegiatan Pengabdian masyarakat dilaksanakan pada Bulan Mei-Juni 2019 dengan sasaran Lansia RT 11 Kelurahan Kenali Asam Bawah. Tujuan dari kegiatan pengabdian ini yaitu: agar lansia lebih memahami tentang masalah-masalah kesehatan yang sering terjadi dan lebih aktif mengikuti posyandu lansia sehingga terwujud "Lansia Sehat dan produktif di Usia Senja".

\section{Pelaksanaan Kegiatan}

Tahapan pelaksanaan kegiatan pengabdian kepada masyarakat ini adalah sebagai berikut:

\section{Persiapan}

a) Menyusun proposal kegiatan pengabdian kepada masyarakat.

b) Pengadaan Poster/media KIE

c) Menyiapkan materi/bahan presentasi tentang pencegahan asam urat dan stroke.

\section{Pelaksanaan Kegiatan}

a) Perkenalan, diskusi tim serta menjelaskan kegiatan yang akan dilakukan

b) Edukasi pada lansia melalui media poster dan leafleat.

c) Tanya jawab

d) Penutupan

\section{Monitoring dan Evaluasi}

Monitoring dan evaluasi (Monev) dilakukan secara langsung kepada sasaran. Cakupan Monev dalam kegiatan ini meliputi monev perencanaan dan pelaksanaan dan evaluasi hasil.

\section{HASIL DAN PEMBAHASAN}

Pelaksanaan kegiatan masyarakat di RT 11 dibantu oleh Mahasiswa/mahasiswi Program Studi D3 Keperawatan STIKes Baiturrahim Jambi, dihadiri oleh 20 orang lansia. Adapun Kegiatan yang telah dilakukan adalah diskusi dengan kader tentang pentingnya posyandu lansia, Penyuluhan tentang Pencegahan Stroke dan 
Asam urat pada Lansia. Pemberian media KIE . Pada tahap evaluasi , Lansia sangat antusias mengikuti kegiatan penyuluhan. Beberapa lansia juga banyak mengajukan pertanyaan tentang pencegahan stroke dan penatalaksanaan asam urat.

Lansia adalah kelompok penduduk berumur tua. Golongan penduduk yang mendapat perhatian atau penglompokan trsendiri ini adalah polulasi berumur 60 tahun.atau lebih. Lanjut usia adalah tahap akhir perkembangan pada daur kehidupan manusia. Lansia identik dengan menurunnya daya tahan tubuh dan mengalami berbagai macam penyakit. Salah satu penyakit yang sering terjadi pada lansia adalah asam urat dan stroke.

Dengan adanya pendidikan kesehatan ini diharapkan lansia tahu tentang pencegahan stroke dan asam urat. Kegiatan pengabdian ini menggunakan media yang sesuai dengan kebutuhan responden. Dari wawancara dengan Responden yang mengalami Asam urat tinggi disebabkan karena banyak konsumsi makanan tinggi kadar asam uratnya, jarang berolah raga sehingga kadar asam urat tidak bisa terbakar menjadi energi, dipicu usia dan juga biasanya makanan tidak sehat tersebut juga mengandung kolesterol tinggi. Sebagai langkah antisipasi agar tidak terkena penyakit asam urat, pola makan teratur untuk kadar lemak rendah, banyak serat baik untuk dilakukan. Hindari juga beberapa makanan dengan kadar asam urat tinggi seperti Jeroan daging sapi, ayam maupun kambing seperti rempela, babat, kikil, hati, ginjal, kelenjar timus, harus dihindari penderita kadar asam urat tinggi. Menu ini kaya akan purin sebagai pemicu asam urat tinggi akibat senyawa kimia pecah menjadi lemak dan zat asam urat sehingga jika dikonsumsi berlebih, tidak baik bagi tubuh dalam tubuh.

Daging merah baik daging sapi maupun kambing juga kaya akan purin dan kolesterol sehingga perlu dikurangi konsumsinya. Idealnya cukup beberapa gram saja selama konsumsi seminggu agar tidak mengganggu kesehatan dari sisi kadar asam urat. Pusat purin adalah pada lemak yang menempel pada daging, sehingga jika mau sehat konsumsi daging, bagian ini harus dibuang. Pengganti daging merah jika Anda adalah maniak daging, bisa diganti dengan daging ayam atau kalkun.

Seafood juga kaya akan purin dan kalium pemicu asam urat tinggi. Menu ini biasanya banyak disajikan dalam bentuk olahan bahan makanan dari udang, kerang, lobster, atau ikan tuna. Jika dilihat dari hasil riset 86 gram lobster bisa support lebih dari 66 miligram kolesterol dan akan makin banyak kolesterol dan purinnya jika digoreng. Hindari stress agar hormon pemicu asam urat tidak berlebih

Stroke dapat terjadi karena seseorang individu yang sehat memiliki faktor risiko. Stroke dapat menyerang kapan saja, mendadak, siapa saja, baik laki-laki atau perempuan, tua atau muda. Diperkirakan satu sampai tiga orang akan mengalami stroke dan satu dari tujuh orang meninggal karena stroke. Insiden stroke timbul bervariasi, tergantung tempat atau negara, waktu, serta penderitanya. Insiden stroke di negara berkembang masih meningkat sedangkan di negara maju cenderung menurun. Faktor risiko stroke ada yang dapat dikendalikan dan ada pula yang tidak dapat dikendalikan. Peningkatan jumlah penderita stroke ini berkaitan dengan perubahan gaya hidup yaitu pola makan yang tidak sehat, konsumsi makanan yang banyak mengandung lemak atau kolesterol. Untuk mencegah stroke yang harus dilakukan oleh adalah diet seimbang dan rendah garam, olahraga teratur, tidak merokok dan tidak minum alcohol, menjaga berat badan agar tetap ideal dan mengontrol tekanan darah secara teratur. 


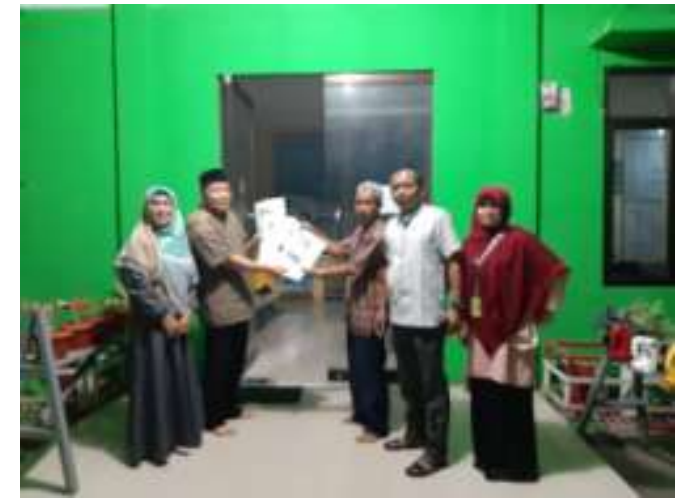

Gambar 1. Pemberian poster

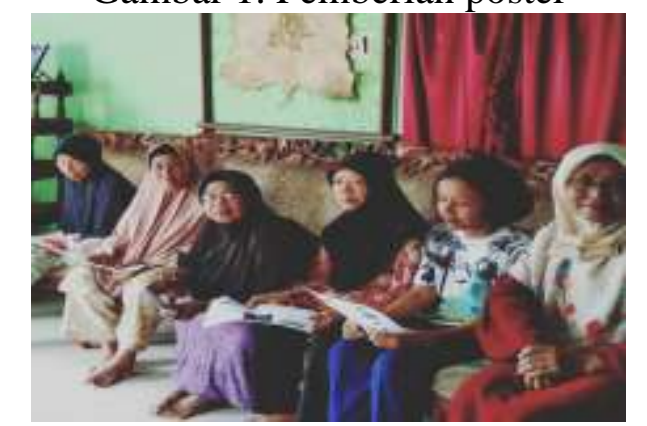

Gambar 2. Pemberian edukasi pada lansia

\section{KESIMPULAN DAN SARAN}

\section{Kesimpulan}

Setelah tim melaksanakan kegiatan pengabdian masyarakat lansia yang hadir mulai mengerti dan memahami tentang penyakit asam urat dan stroke .

\section{Saran}

Diharapkan kepada Warga khususnya Lansia di kelurahan Kenali Asam Bawah agar terus menjaga dan meningkatkan pola hidup sehat sehingga terhindar dari penyakit dan terus mencari informasi baik dari Petugas kesehatan maupun media lainnya sehingga dapat meningkatkan pengetahuan warga terhadap masalahmasalah kesehatan yang sering terjadi di masyarakat .

\section{UCAPAN TERIMAKASIH}

Tim Pengabdian mengucapkan terimakasih kepada STIKes Baiturrahim Jambi atas dukungan moril serta materiil sehingga kegiatan ini dapat terlaksana dengan baik.

\section{DAFTAR PUSTAKA}

Azizah, Lilik Ma'rifatul. (2011). Keperawatan Lanjut Usia, Ed.1. Graha Ilmu. Yogyakarta.

Depkes RI, 2010, Pedoman Umum Pengembangan Desa dan Kelurahan Siaga Aktif. Jakarta : Pusat Promosi Kesehatan Sekretaris Jenderal Kementerian Kesehatan RI

Darmojo,B.R, dan Martono.H. 2004. Buku Ajar Geriatri. Balai Penerbit FKUI. Jakarta.

Kemenkes RI,2019. Infodatin Stroke, Jakarta, 2019

Kemenkes RI, 2019 Riset Kesehatan Dasar tahun 2018, Indonesia

M Maimaznah, TY Fatmawati, 2020. Lansia Sehat Bebas Hipertensi di Kelurahan Kenali Asam Kota Jambi, Jurnal Abdimas Kesehatan (JAK) Vol 2, , No. 1, Januari 2020. http://jak.stikba.ac.id/index.php/jak/a rticle/view/100. diakses tanggal 10/04/2020.

Nugroho, Wahjudi. (2014). Keperawatan Gerontik \& Geriatrik, Ed.3. EGC. Jakarta.

Notoatmodjo, S. 2012. Promosi Kesehatan dan Perilaku Kesehatan. Jakarta: PT Rineka Cipta.

Padila. 2013. Buku Ajar Keperawatan Gerontik. Numed. Yogyakarta. 